\title{
THE EFFECT OF THE NATURE OF LIGANDS ON THE REACTIVITY OF THE METAL-CARBON BOND IN COBALT CHELATES
}

\author{
G. Costa \\ Institute of Chemistry. University of Trieste. Trieste, Italy
}

\begin{abstract}
After a short account of the model approach to the coordination chemistry of Vitamin $\mathrm{B}_{12}$. previous evidence concerning the influence of organic groups as axial ligands on ground state properties and reactivity of several series of cobalt chelates with tetradentate equatorial macrocycles is summarized. The recent results dealing with the influence of the nature of the equatorial chelating agent on ground state properties of the molecule and on coordination chemistry and reactivity at the axial positions are compared. All properties dependent on the macrocyclic ligand show a consistent trend which can be interpreted in terms of the electron affinity of the particle mainly influencing the equilibria involving the cobalt-axial ligand bond, as well as the reaction mechanism at the cobalt-carbon bond.
\end{abstract}

The interest in the chemistry of cobalt chelates, from which stable $\sigma$ cobalt-carbon bonds can be produced, was at first mainly due to striking analogies with Vitamin $\mathbf{B}_{12}$ group complexes where organic groups are directly bonded to the metal atom ${ }^{1}$. Compounds containing conjugated systems which act as bisbidentate or tetradentate chelating agents lying in the equatorial plane of square pyramidal or octahedral structures were thus proposed as models for the naturally occurring complexes of the corrin ring $1,2,3$.

The relevant properties induced by the conjugate chelating system are not limited to the stability of the cobalt-carbon bond in a formally $\mathrm{Co}^{\text {III }}-\mathrm{d}^{6}$ low spin complex but also include, for example, the reversible formation of oxygen adducts from $\mathrm{Co}^{11}-\mathrm{d}^{7}$ paramagnetic complexes ${ }^{4-8}$ and the relative stability of the $\mathrm{Co}^{\mathrm{I}}-\mathrm{d}^{8}$ oxidation state. A variety of surprising new reactions which are still being currently reported stimulated studies directed to the understanding of the mechanistic concepts underlying this versatile and unusual chemical behaviour. This aim was pursued through the study of the coordination chemistry of the transition metal atom in these chelates. The effect of the axial ligand has already been discussed in a series of derivatives with a single equatorial ligand including the Vitamin $\mathrm{B}_{12}$ group complexes ${ }^{9}$ and bisdimethylglyoximates ${ }^{1,10-14}$. We prepared a number of complexes with different tetradentate ligands, all of which induce the same type of 


\section{G. COSTA}

chemical behaviour, in order to study the effect of different electronic situations in the equatorial plane on the trend of relevant physico-chemical properties of the complexes (Figure 1).
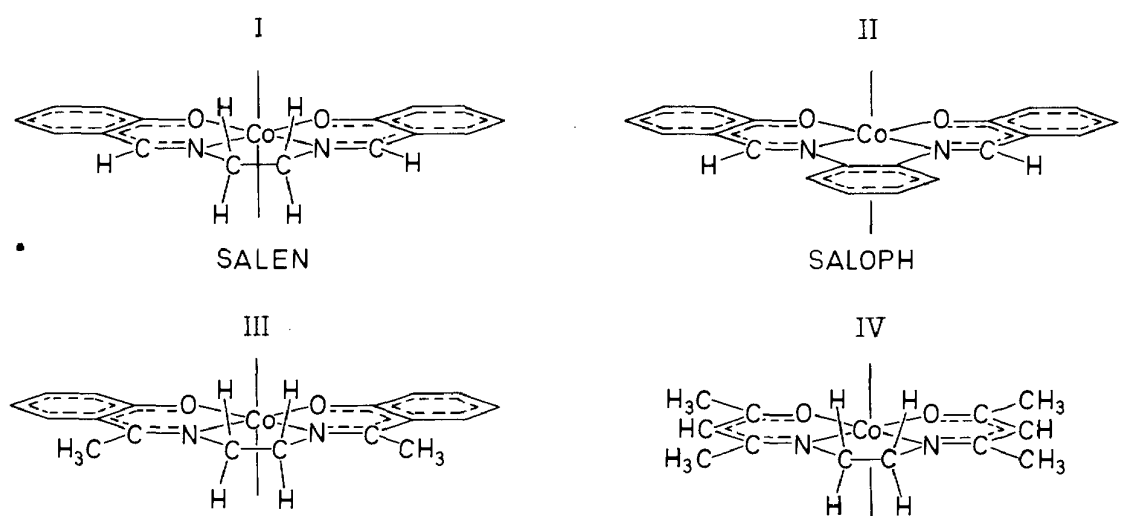

$7,7^{\prime}-\left(\mathrm{CH}_{3}\right)_{2}-\mathrm{SALEN}$

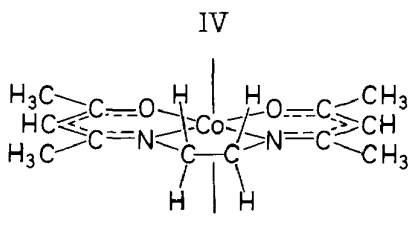

BAE

$\mathrm{V}$

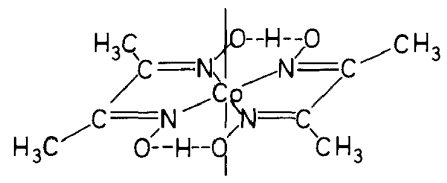

$(\mathrm{DH})_{2}$

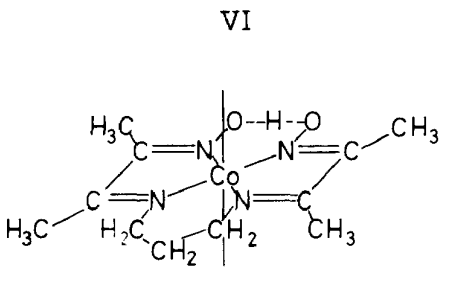

(DO) $(\mathrm{DOH}) \mathrm{pn}$

Some of the reactions giving organometallic derivatives, stabilized by chelating dianions, are reported on Figure $2^{15-26}$. Organometallic derivatives can be prepared from potential carbanions as in the Grignard reaction from $\mathrm{Co}^{\mathrm{III}}$ chelates, or by disproportion or homolytic reaction from $\mathrm{Co}^{\mathrm{II}}$ chelates, or by oxidative addition to $\mathrm{Co}^{\mathrm{I}}$ chelates.

It now seems appropriate to briefly summarize previous evidence concerning the intluence of the organic group as axial ligand, on the ground state properties and on the reactivity of the present chelates, and then to consider recent studies on the influence of the equatorial ligand. We shall also report on electrochemical investigations giving insight into thermodynamic quantities related to the change of the number of electrons and on the nature of intermediates and products of the redox reaction. We shall conclude with some considerations of the role of the equatorial ligand in determining the reaction mechanism at the cobalt-carbon bond. 


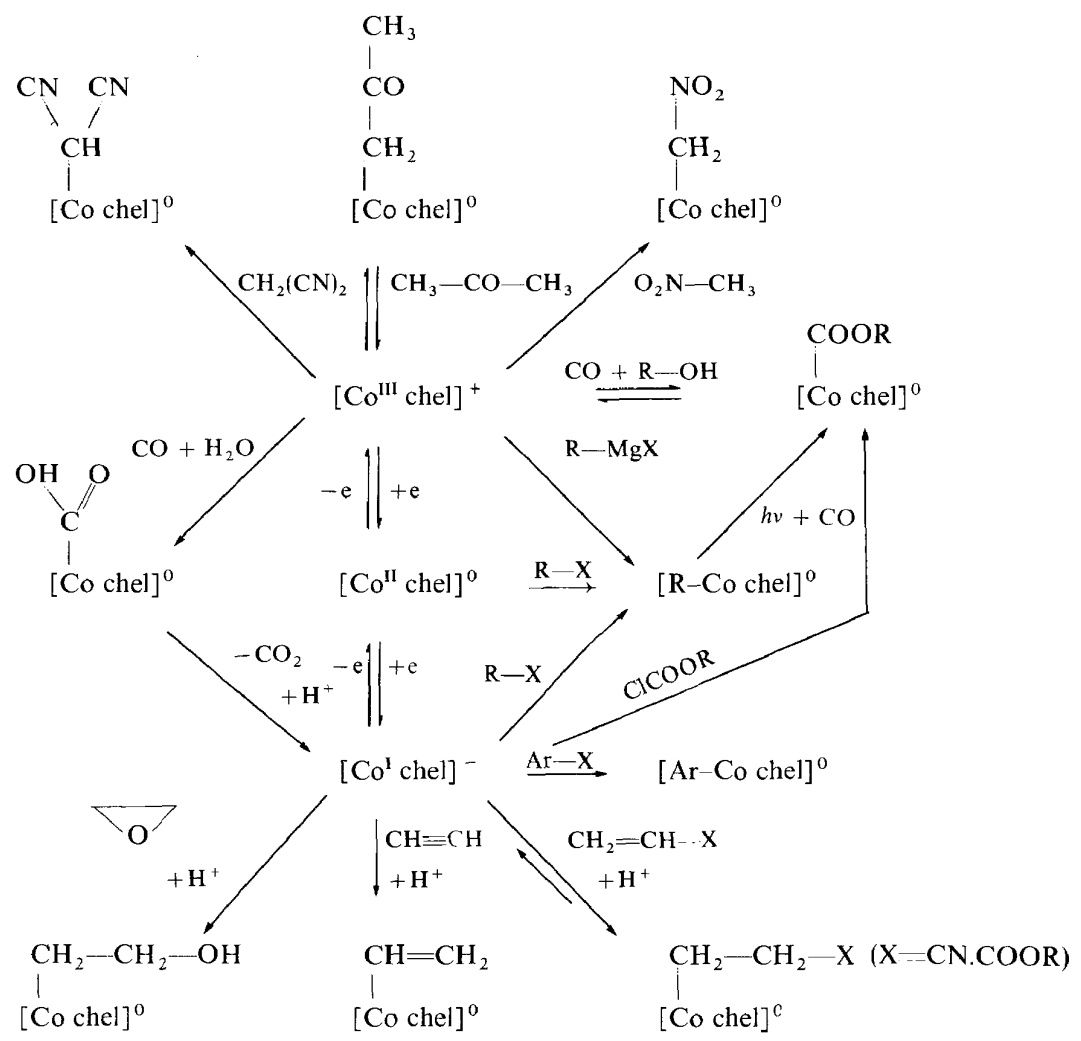

Figure 2

From a consideration of the structural features resulting from several $\mathrm{x}$-ray diffraction determinations we can observe that changes of the nature of axial ligands do not seem to produce noticeable effects on the interatomic distances in the chelating rings ${ }^{27}$. What is even more interesting is that changes in the formal oxidation state of the cobalt atom, as in organometallic derivatives $\left[\mathrm{RCo}^{\mathrm{III}} \mathrm{chel}\right]$, as compared with tetracoordinated
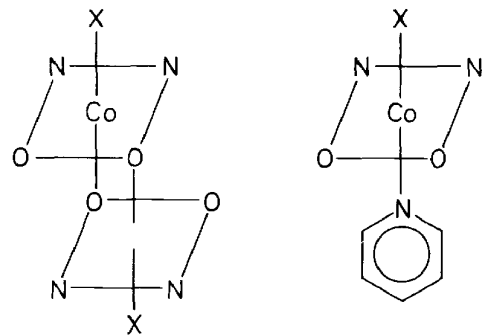

Figure 3 


\section{G. COSTA}

$\left[\mathrm{Co}^{\mathrm{II}}\right.$ chel], do not cause significant differences in cobalt-oxygen or cobaltnitrogen distances (Table 1). Evidence of the influence of an organic group upon the trans ligand was pointed out from the increase of metal trans axial bond lengths such as the axial cobalt-oxygen distance in the dimeric compound $\left[\mathrm{CH}_{3} \mathrm{CH}_{2} \mathrm{Co}(\text { salen) })\right]_{2}(2.342 \AA)$ as compared with [ClCo(salen) $]_{2}$ $(1.995 \AA)$ and from the axial cobalt-pyridine-nitrogen bond length in the derivative $\left[\mathrm{CH}_{2}=\mathrm{CHCo} \text { (salen)pyr }\right]_{2} \quad(2.119 \AA)$ as compared with $\left[\mathrm{CH}_{3} \mathrm{OCo}\right.$ (salen)pyr] $(2.031 \AA)^{27}$ (Figure 3 ).

Table 1 . Dependence of metal-ligand borid lengths $(\AA)$ on formal oxidation state of the metal atom

\begin{tabular}{|c|c|c|}
\hline & & $\mathrm{Co}^{\mathrm{III}}$ \\
\hline \multicolumn{2}{|c|}{$[\mathrm{Co}(\mathrm{bae})] \cdot \mathrm{C}_{6} \mathrm{H}_{6}$} & {$\left[\mathrm{CH}_{3} \mathrm{Co}(\mathrm{bae})\right]$} \\
\hline $\mathrm{Co}-\mathrm{N}$ & 1.864 & 1.860 \\
\hline $\mathrm{Co}-\mathrm{O}$ & 1.854 & 1.874 \\
\hline \multicolumn{2}{|c|}{$[\mathrm{Co}($ salen$) \mathrm{py}]$} & {$\left[\mathrm{C}_{2} \mathrm{H}_{5} \mathrm{Co}(\text { salen })\right]_{2}$} \\
\hline $\mathrm{Co}-\mathrm{N}$ & 1.90 & 1.889 \\
\hline $\mathrm{Co}-\mathrm{O}$ & 1.90 & 1.90 \\
\hline \multicolumn{2}{|c|}{$\mathrm{Co}$-bis L-histidinate- $\mathrm{H}_{2} \mathrm{O}^{28}$} & Co-bisglicylglicinate cobaltate ${ }^{29}$ \\
\hline $\mathrm{Co}-\mathrm{N}$ & $2.12-2.14$ & 1.87 \\
\hline $\mathrm{Co}-\mathrm{O}$ & $2.07-2.15$ & $1.93-1.98$ \\
\hline
\end{tabular}

Cis and trans influence could be proved in principle from bond stretching force constants within the equatorial plane or in the trans axial ligand. Thus, in the series of cyano-corrinoids and pentacyano-organo cobaltate(III) the trans influence of alkyl groups was pointed out previously using the $\mathrm{CN}$ stretching frequency as a probe and showing that it is sensitive to changes in the nature of the trans organic group ${ }^{30,31}$.

On changing from anions such as $\mathrm{OH}^{-}\left(v_{\mathrm{CN}}=2130 \mathrm{~cm}^{-1}\right)$ to organic groups as ligands in the trans position to the cyano group in cobalamines the stretching frequency becomes $v_{\mathrm{CN}}=2110 \mathrm{~cm}^{-1}$ for the ethinyl group, $v_{\mathrm{CN}}=2093 \mathrm{~cm}^{-1}$ for the vinyl, 2088 and $2082 \mathrm{~cm}^{-1}$ for the methyl and ethyl groups respectively, approaching the value of $2079 \mathrm{~cm}^{-1}$ which is characteristic of the free cyano group.

Further evidence for the ground state reciprocal effect of the ligands was drawn from ${ }^{1} \mathrm{H}$ n.m.r. measurements. The chemical shift of $\mathrm{C}(10)$ hydrogen in the corrin ring is shifted upfield with increasing donor power of the axial ligand ${ }^{32}$. The same effect was observed for the methyl hydrogens of the dimethylglyoximates $^{33}$ and also for the methene hydrogens of the bae ligand as influenced either by a substituted phenyl group or by an alkyl group in the trans position ${ }^{34,35}$. On the other hand, interactions between axial ligands are shown by the increase of the chemical shift of cobalt $-\mathrm{CH}_{3}$ hydrogens in $\left[\mathrm{CH}_{3} \mathrm{Co}(\mathrm{bae}) \mathrm{L}\right]$ with increasing basicity of the trans ligand $(\mathrm{L}=$ substituted pyridine $)$. 


\section{REACTIVITY OF THE METAL-CARBON BOND IN COBALT CHELATES}

\section{THE INFLUENCE OF THE ORGANIC GROUP ON}

\section{THERMODYNAMIC AND KINETIC ASPECTS OF REACTIVITY}

One of the most important aspects of the influence of axial ligands is represented by the equilibria between five and six-coordinated forms. This was shown in the bae series with different organic groups and Lewis bases as trans axial ligands as well as in the substituted phenyl-bae chelates with pyridine as the labilized trans ligand ${ }^{36,38}$ (Table 2). Trans labilizing influence

Table 2. Thermodynamic trans influence of axial ligands on the equilibrium quotient for the reaction

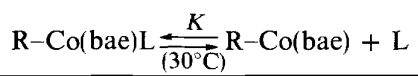

\begin{tabular}{|c|c|c|c|c|c|}
\hline \multirow{2}{*}{$\mathrm{L}$} & \multirow{2}{*}{$\mathrm{p} K$} & \multicolumn{4}{|c|}{$\mathrm{R}$} \\
\hline & & $\mathrm{R}=\mathrm{C}_{2} \mathrm{H}_{5}$ & $\mathrm{CH}_{3}$ & $\mathrm{CH}_{2}=\mathrm{CH}$ & $\mathrm{C}_{6} \mathrm{H}_{5}$ \\
\hline$p-\mathrm{ClC}_{6} \mathrm{H}_{4} \mathrm{NH}_{2}$ & 3.98 & 1.14 & 0.26 & 0.19 & 0.17 \\
\hline $\mathrm{C}_{6} \mathrm{H}_{5} \mathrm{NH}_{2}$ & 4.58 & 0.87 & 0.20 & 0.18 & 0.12 \\
\hline$p-\mathrm{CH}_{3} \mathrm{C}_{6} \mathrm{H}_{4} \mathrm{NH}_{2}$ & 5.12 & 0.68 & 0.14 & 0.11 & 0.08 \\
\hline $\mathrm{C}_{5} \mathrm{H}_{5} \mathrm{~N}$ & 5.23 & 0.24 & 0.02 & 0.02 & 0.05 \\
\hline $4-\mathrm{CH}_{3} \mathrm{C}_{6} \mathrm{H}_{4} \mathrm{~N}$ & 6.02 & 0.21 & 0.12 & 0.02 & 0.19 \\
\hline
\end{tabular}

Table 3. Thermodynamic trans influence of tertiary phosphines on the equilibrium quotient for the reaction

\begin{tabular}{lccc}
\multicolumn{3}{c}{$\left[\mathrm{Co}(\mathrm{chel}) \mathrm{PR}_{3}\right]^{+}+\mathrm{NO}_{2}^{-} \stackrel{K}{\rightleftharpoons}\left[\mathrm{Co}(\mathrm{chel})\left(\mathrm{PR}_{3}\right)\left(\mathrm{NO}_{2}\right)\right]^{0}$} \\
\hline $\mathrm{PR}_{3}$ & $\sigma^{\star}$ & (bae) & (salen) \\
$\mathrm{PPh}_{3}$ & +1.80 & 4.69 & 5.57 \\
$\mathrm{PPh}_{2} \mathrm{Et}$ & +1.10 & 3.54 & 3.88 \\
$\mathrm{PBu}_{3}$ & -0.39 & 2.87 & 3.09 \\
\hline
\end{tabular}

of tertiary phosphines was found to be particularly strong (Table 3$)^{37}$. Five-coordinated bae chelates with either type of axial ligands were in fact isolated in our laboratory as well as the five-coordinated organometallic derivatives of $\mathrm{Co}-$ salen $^{15-18}$.

Table 4. Kinetic trans effect of organic groups as axial ligands

$\left[\mathrm{R}-\mathrm{Co}\{(\mathrm{DO})(\mathrm{DOH}) \mathrm{pn}\} \mathrm{H}_{2} \mathrm{O}\right]^{+}+\mathrm{Y} \rightarrow[\mathrm{R}-\mathrm{Co}\{(\mathrm{DO})(\mathrm{DOH}) \mathrm{pn}\} \mathrm{Y}]^{+}+\mathrm{H}_{2} \mathrm{O}$

$$
\begin{gathered}
\mathrm{M}-\mathrm{H}_{2} \mathrm{O} \underset{k_{2}}{\stackrel{k_{1}}{\rightleftharpoons}} \mathrm{M}+\mathrm{H}_{2} \mathrm{O} \\
(\mathrm{Y}=\text { imidazole })
\end{gathered}
$$

\begin{tabular}{lc}
\hline \multicolumn{1}{c}{$\frac{k_{1}\left(\mathrm{sec}^{-1}\right)}{2.6 \pm 0.3}$} \\
\hline $\mathrm{C}_{6} \mathrm{H}_{5}$ & $24.8 \pm 5.6$ \\
$\mathrm{CH}_{3}$ & $226 \pm 28$ \\
$\mathrm{C}_{6} \mathrm{H}_{5} \mathrm{CH}_{2}$ & $251 \pm 23$ \\
$\mathrm{C}_{2} \mathrm{H}_{5}$ & $602 \pm 139$ \\
$\mathrm{n}^{-} \mathrm{C}_{3} \mathrm{H}_{7}$ & \\
\hline
\end{tabular}




\section{G. COSTA}

The influence of the organic group as a ligand was recently pointed out in the kinetic trans effect ${ }^{39-41}:$ in a series of organometallic derivatives of the (DO) $(\mathrm{DOH})$ pn ligand the dissociation rate in the lim $\mathrm{S}_{\mathrm{N}} 1$ process increases with increasing donor power of the organic group, $\mathrm{C}_{6} \mathrm{H}_{5}<\mathrm{CH}_{3}<$ $\mathrm{C}_{6} \mathrm{H}_{5} \mathrm{CH}_{2}<\mathrm{C}_{2} \mathrm{H}_{5}<\mathrm{n}-\mathrm{C}_{3} \mathrm{H}_{7}$ (Table 4).

\section{TRANSMISSION OF ELECTRONIC EFFECTS}

All the data regarding the influence of the axial ligand upon the ground state properties in these complexes led to the conclusion that the charge donation to the metal atom is efficiently transmitted to other ligands either equatorial or trans axial ${ }^{42}$.

In so far as chemical shifts represent changes in electron density, the ${ }^{1} \mathrm{H}$ n.m.r. results were interpreted assuming that the greater the charge donation to the metal the greater the electron density on protons in the equatorial plane and in the trans ligand.

The changes of group stretching frequencies within the axial ligand were also interpreted as an indirect consequence of the transmission of the electronic effects from one axial ligand to the other through the cobalt atom. The same assumption is in complete agreement with the experimental data on thermodynamic and kinetic aspects of coordination chemistry of the chelates.

The stabilization of a lower coordination number and the existence of five-coordinated species was thus attributed to the labilizing trans influence of one axial ligand due to increased negative charge density on the metal atom. This is in fact consistent with the lower interaction between the cobalt atom and the axial ligands in the $\mathrm{Co}^{\mathrm{II}}$ complexes. In organometallic derivatives the organic group can be formally considered, from the point of view of the coordination chemist, as a carbanion coordinated to the cobalt atom in the $\mathrm{Co}^{\mathrm{III}}$ oxidation state. From experimental data on cis and trans influence it is apparent that the organic group is a very strong donor as compared with most of the conventional ligands. It was pointed out that as a consequence of the transmission of charge to the metal, the actual electronic charge could be closer to that of a lower oxidation state and the metalcarbon bond could thus be represented by the resonance forms $\mathrm{CH}_{3}^{-}-\mathrm{Co}^{\mathrm{III}}$; $\mathrm{CH}_{3}-\mathrm{Co}^{\mathrm{II}} ; \mathrm{CH}_{3}^{+}-\mathrm{Co}^{\mathrm{I42}}$. To what extent can the relative weight of these resonance forms be altered? In other words, how can the nature of the equatorial ligand or that of the organic group itself determine the ground state charge distribution within the cobalt-carbon bond? How far is the reactivity at the cobalt-carbon bond affected? Useful information about these problems can be obtained by studying the thermodynamic aspects and chemical consequences of the transfer of one electron to the particle. This change in the total electronic charge concerns mainly the cobalt-carbon bond properties. We shall thus start considering in the next section the influence of axial ligands on the redox potentials.

\section{THE INFLUENCE OF AXIAL LIGANDS ON REDOX POTENTIALS}

The cobalt chelates with conjugated chelating systems can be shown to 
undergo, in suitable experimental conditions, reversible one electron transfer corresponding to the $\mathrm{Co}^{\mathrm{III}}-\mathrm{Co}^{\mathrm{II}}$ and $\mathrm{Co}^{\mathrm{II}}-\mathrm{Co}^{\mathrm{I}}$ reduction steps. The first electrochemical investigations ${ }^{43,44}$ were carried out on complexes of the type $\left[\mathrm{Co}(\mathrm{chel}) \mathrm{L}_{2}\right]^{+}$and $\left.[\mathrm{Co}\{\mathrm{DO})(\mathrm{DOH}) \mathrm{pn}\} \mathrm{L}_{2}\right]^{2+}$. The organometallic complexes of the type $[\mathrm{R}-\mathrm{Co}(\mathrm{chel}) \mathrm{L}]^{0}$ or $[\mathrm{R}-\mathrm{Co}\{(\mathrm{DO})(\mathrm{DOH}) \mathrm{pn}\} \mathrm{L}]^{+}$also exhibit in aprotic solvents two generally distinguishable one electron redox processes due to the changes of formal oxidation state $\mathrm{Co}^{\mathrm{III}}-\mathrm{Co}^{\mathrm{II}}-\mathrm{Co}^{\mathrm{I}}$.

For the complexes with chelating dianions the reduction schemes are:

$$
\begin{aligned}
& {\left[\mathrm{Co}^{\text {III }}(\text { chel }) \mathrm{L}_{2}\right]^{+\stackrel{+e}{\rightleftharpoons}}\left[\mathrm{Co}^{\text {II }}(\mathrm{chel}) \mathrm{L}_{2}\right]^{0} \stackrel{+\mathrm{e}}{\rightleftharpoons \mathrm{e}}\left[\mathrm{Co}^{\mathrm{I}}(\mathrm{chel}) \mathrm{L}_{2}\right]^{-}} \\
& {[\mathrm{R}-\mathrm{Co}(\mathrm{chel}) \mathrm{L}]^{0} \underset{\rightleftharpoons \mathrm{e}}{\stackrel{+\mathrm{e}}{\rightleftharpoons}}[\mathrm{R}-\mathrm{Co}(\mathrm{chel}) \mathrm{L}]^{-\stackrel{+e}{\rightleftharpoons}}[\mathrm{R}-\mathrm{Co}(\mathrm{chel}) \mathrm{L}]^{2-}}
\end{aligned}
$$

The electron transfers (1) can be followed by chemical reactions involving release or exchange of Lewis base $\mathrm{L}^{45}$ and the electron transfers (2) can be followed by chemical reactions involving both the organic group $\mathrm{R}$ and $\mathrm{L}^{46,47}$. The same scheme is valid for complexes with (DO)(DOH)pn monoanionic ligand.

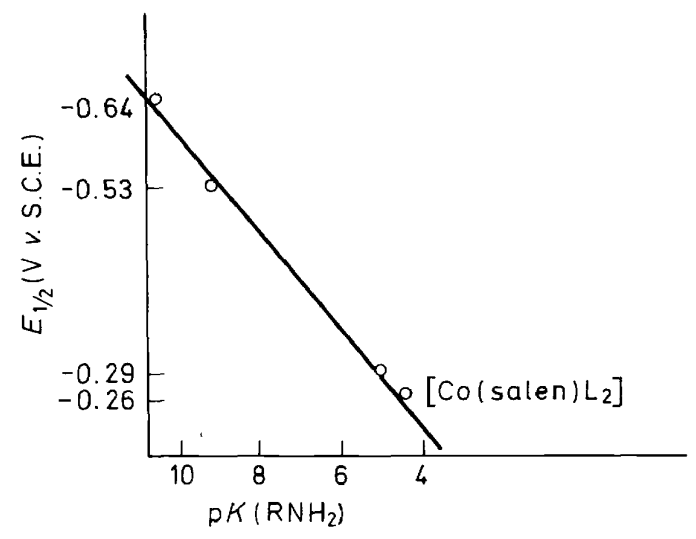

Figure 4

By contrast with the conventional cobaltammines almost all of the chelates examined are characterized by fast electron exchange processes at the dropping mercury or platinum electrode ${ }^{48}$. The primary electrode reaction products are often unstable but under suitable conditions the chemical reactions following the electron transfer are slow enough to be studied separately from the electron transfer process. The half-wave potentials $\left(E_{\frac{1}{2}}\right)$ of the waves obtained under well-controlled conditions thus provide thermodynamic information related to the change in oxidation state of the particle ${ }^{49}$. When the protonation constants of the axial ligands (either the Lewis bases or the carbanions $\mathrm{R}^{-}$) are plotted against the half-wave potential due to the first reduction step $\mathrm{Co}^{\mathrm{III}} \perp \mathrm{Co}^{\mathrm{II}}\left(E_{\frac{1}{2}}^{\mathrm{I}}\right)$ strikingly linear free energy relationships are obtained (Figure 4). It is interesting to note that the slopes of the straight lines for $[\mathrm{R}-\mathrm{Co}(\mathrm{chel}) \mathrm{L}]^{0}$ and for some of the corresponding $\mathrm{R}-\mathrm{Hg}$ subvalent species are very similar (Figure 5). 


\section{G. COSTA}

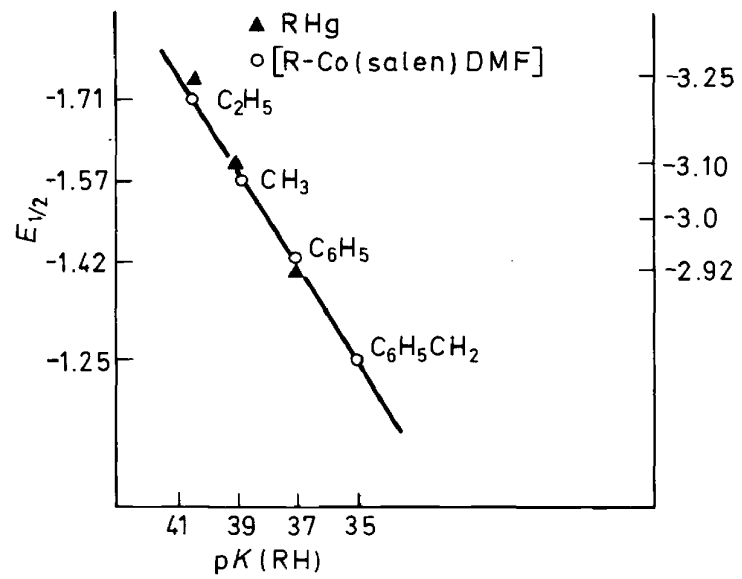

Figure 5

The half-wave potentials for the organocobalt chelates are more cathodic than the corresponding non-organometallic chelates but much less cathodic than those of the corresponding $\mathrm{R}-\mathrm{Hg}$ organometallics. So the range of the $E_{\frac{1}{2}}^{\mathbf{I}}$ lies between that of $\mathrm{R}-\mathrm{Hg}$ and that of $\left[\mathrm{Co}(\mathrm{chel}) \mathrm{L}_{2}\right]^{+}$.

Owing to small $\pi$-bonding and polarization interaction and very low metal-carbon dissociation energies it was suggested that the half-wave potential for the reduction of the organomercury subvalent species $\mathrm{R}-\mathrm{Hg}$ reflects essentially the stability of the corresponding carbanion ${ }^{50}$. However, in the case of the organocobalt chelates the electron affinity of the cobalt chelate drastically decreases owing to the strong charge donation from the organic group.

A linear free energy relationship between donor power of the organic group and half-wave potential of the first reduction step was observed not only for the complexes of the chelating dianions but also for the derivatives of (DO) (DOH)pn (Figure 6).

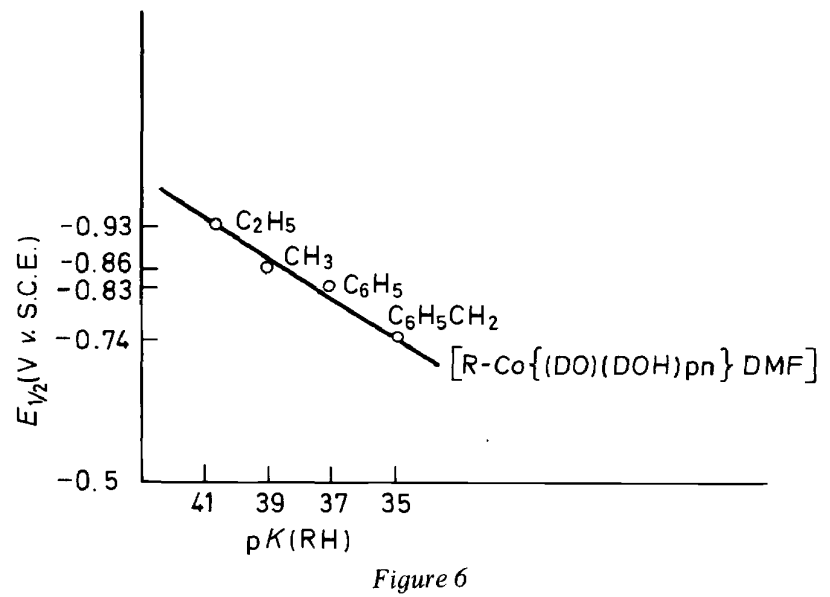


The products of the one electron reduction of the organometallic chelates are generally labile. The fate of the reduction product (which is a monoanion $[\mathrm{R}-\mathrm{Co}(\mathrm{chel}) \mathrm{L}]^{-}$or a non-charged complex $\left.[\mathrm{R}-\mathrm{Co}\{(\mathrm{DO})(\mathrm{DOH}) \mathrm{pn}\} \mathrm{L}]^{0}\right)$ depends on the nature of both the equatorial and the axial ligands. The most important process is the reductive cleavage of the cobalt-carbon bond.

In the case of alkyl derivatives of salen the reduction product is decomposed in DMF while the corresponding phenyl derivatives are more stable:

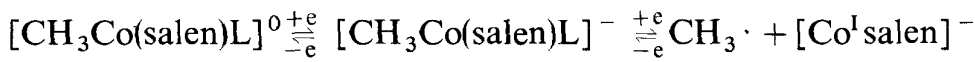

$$
\begin{aligned}
& {\left[\mathrm{C}_{6} \mathrm{H}_{4} \mathrm{Co}(\text { salen)L }]^{0} \stackrel{+\mathrm{e}}{=}\left[\mathrm{C}_{6} \mathrm{H}_{4} \mathrm{Co}(\text { salen }) \mathrm{L}\right]^{-\stackrel{+e}{-\mathrm{e}}}\left[\mathrm{C}_{6} \mathrm{H}_{5} \mathrm{Co}(\text { salen }) \mathrm{L}\right]^{2-}\right.}
\end{aligned}
$$

On the other hand, in these cases the organic group in [R-Co(chel)L] seems to be much more reactive than in the corresponding $\left[R-\mathrm{Co}^{\text {III }}(\mathrm{chel}) \mathrm{L}\right]^{\mathrm{o}}$ chelates. This is in agreement with higher lability of the formal carbanion coordinated to the cobalt in a lower oxidation state.

These results can be used to obtain two types of information: the first consists of the quantitative evaluation of the effects of charge donation from the axial ligand on the increase in energy of the molecular orbital accepting the electron, and the second concerns the reactivity of the cobalt-carbon bond in the product of the electron transfer. This process can be proposed as a model for the reductive cleavage reaction.

We shall now turn to the other aspect of the problem of the influence of the ligands, that is the effect of the equatorial ligand on the properties of the cobalt-carbon bond.

\section{GROUND STATE, THERMODYNAMIC AND KINETIC CIS EFFECT OF THE EQUATORIAL LIGAND}

The most relevant aspects of the chemical behaviour of the chelates we are discussing, either the $\mathrm{Co}^{\mathrm{III}}$ organometallic compounds, as well as the $\mathrm{Co}^{\mathrm{II}}-\mathrm{O}_{2}$ adducts, or $\mathrm{Co}^{\mathbf{I}}$ derivatives, all reside in the versatile reactivity of the axial position. The characteristics of the corresponding coordination bond appear to be critically dependent on the nature of the chelating system (Table 5). An examination of carbonyl stretching frequencies shows the influence of the equatorial ligand on the ground state charge distribution in the axial organic ligand for a series of acetyl and methoxocarbonyl derivatives both in the five-coordinated and in the six-coordinated complexes ${ }^{3}$. The results are consistent with the assumption that the decrease of $v_{\mathrm{C}=\mathrm{O}}$ in going from the (DO) $(\mathrm{DOH})$ pn to bae ligands would reflect an increasing overall donor power of the equatorial ligand transmitted to the axial ligand through the cobalt atom. These data can be compared with an influence of a thermodynamic nature: that of different equatorial ligands on the $\mathrm{p} K$ 's of the corresponding aquocomplexes. In agreement with the assumption of an overall charge donation from the equatorial ligand, transmitted to the metaloxygen bond, the $\mathrm{pK}$ increases in the same order as the carbonyl stretching frequency decreases.

A cis labilizing effect of the equatorial ligand was also inferred from the fact that the five-coordinated organometallic $\mathrm{Co}^{\text {III }}$ complexes are obtained more easily with the bae, which gives off the coordinated water at $80^{\circ} \mathrm{C}$, than 
Table 5

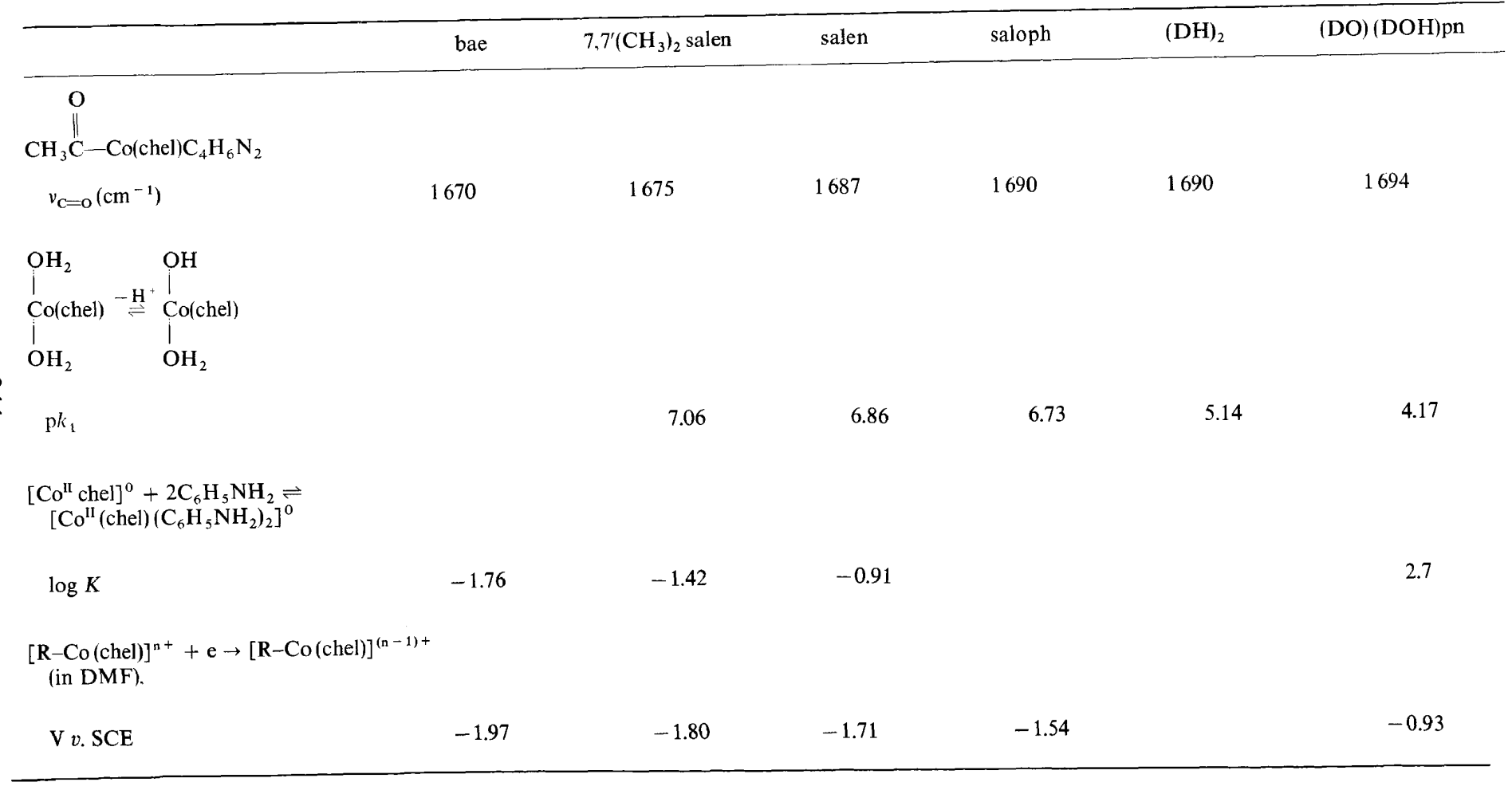


with salen, which loses its coordinated water at $150^{\circ} \mathrm{C}$. Furthermore, the bisdimethyglyoximates and (DO)(DOH)pn derivatives give only hexacoordinated complexes ${ }^{15-18,51}$ or dimers.

From the exchange equilibrium of the axial ligand in $\mathrm{Co}^{\mathrm{II}}$ complexes of the type $\left[\mathrm{Co}^{\mathrm{II}}(\mathrm{chel}) \mathrm{L}_{2}\right]^{0}$ the trend of coordinating power to the axial position in $\mathrm{Co}^{\text {II }}$ derivatives was found to be (DO) $(\mathrm{DOH})$ pn $>$ salen $>7,7^{\prime}\left(\mathrm{CH}_{3}\right)_{2}$ salen $>\mathrm{bae}^{45}$ in agreement with the general trend of the labilization of the axial ligand.

It is interesting to observe that no evidence is available for equilibria involving the cobalt-carbon bond as influenced by the equatorial ligand.

As far as the kinetic cis effect is concerned, striking differences were found to exist between corrinoids and other conventional cobalt complexes. Ligand substitutions are slow in pentacyano and pentammino-complexes by contrast with the extremely rapid reactions generally found in cobalamines ${ }^{52}$. Very fast reactions appear to take place also in salen and bae derivatives.

\section{THE INFLUENCE OF EQUATORIAL LIGANDS ON REDOX POTENTIALS}

The effect of an equatorial ligand can be clearly shown in the half-wave potentials of the $\mathrm{Co}^{\mathrm{III}}-\mathrm{Co}^{\mathrm{II}}$ and $\mathrm{Co}^{\mathrm{II}}-\mathrm{Co}^{\mathrm{I}}$ redox processes. The half-wave

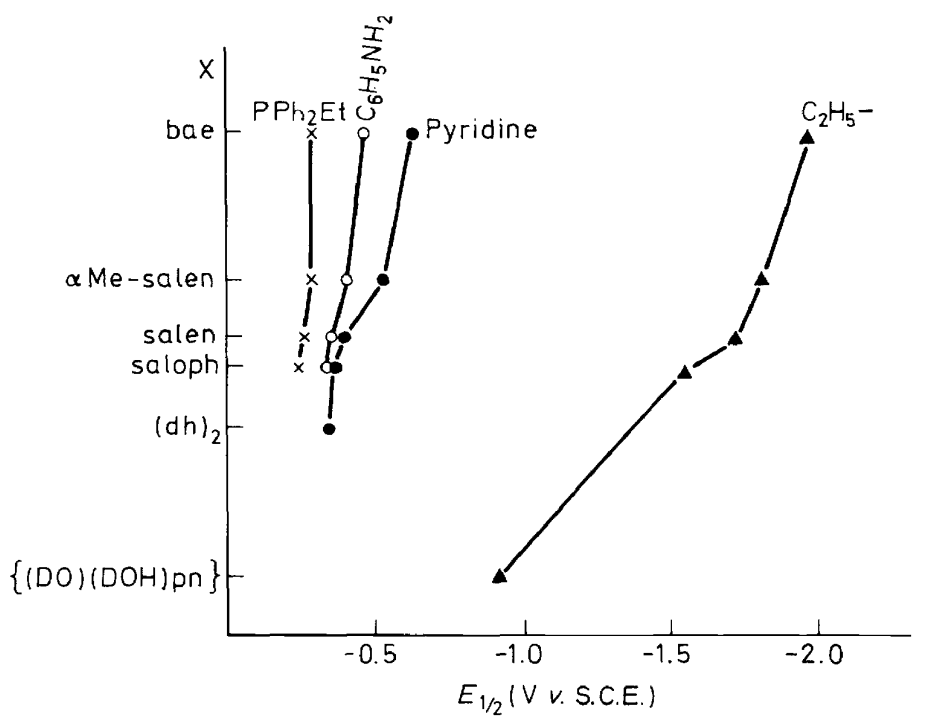

Figure 7

potentials $E_{\frac{1}{2}}^{1}$ for complexes [Co(chel)L $\left.\mathrm{L}_{2}\right]^{+}\left(\mathrm{L}=\mathrm{C}_{6} \mathrm{H}_{5} \mathrm{NH}_{2}\right)$ were plotted against an empirical parameter $\mathrm{x}$, related to the nature of the equatorial ligand, to give a linear relationship of the type $E_{\frac{1}{2}}=\mathrm{ax}+\mathrm{b}$ where $\mathrm{a}$ and $\mathrm{b}$ are constants (Figure 7). 


\section{G. $\operatorname{COSTA}$}

The equatorial ligands order is the same in all cases but its influence on $E_{\frac{1}{2}}^{\mathrm{I}}$ is smaller in the $[\mathrm{Co}(\text { chel }) \mathrm{L}]^{+}$complexes, having Lewis bases such as tertiary phosphines, aniline or pyridine as axial ligands, than in $[\mathrm{R}-\mathrm{Co}(\mathrm{chel}) \mathrm{L}]^{0}$ and $[\mathrm{R}-\mathrm{Co}\{(\mathrm{DO})(\mathrm{DOH}) \mathrm{pn}\} \mathrm{L}]^{+}$complexes $^{44,46,53}$. In contrast the half-wave potentials $E_{\frac{1}{2}}^{\mathrm{I}}$ corresponding to the $\mathrm{Co}^{\mathrm{II}}-\mathrm{Co}^{\mathrm{I}}$ reduction step are influenced to the same remarkable extent both in the complexes having the above Lewis bases as axial ligands and in the corresponding organometallic derivatives. The plots of $E_{\frac{1}{2}}^{\frac{\mathrm{I}}{2}}$ against the same parameter $\mathrm{x}$ are

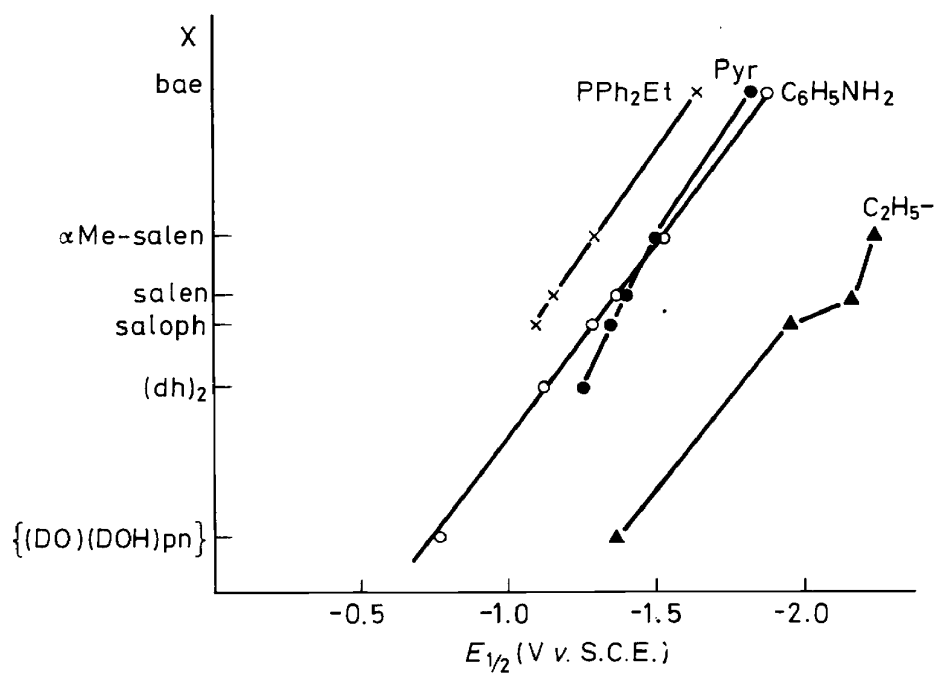

Figure 8

reported in Figure 8. Apparently, the decreased strength of the cobalt axial ligand bond in the $\left[\mathrm{Co}^{\mathrm{II}}(\mathrm{chel}) \mathrm{L}_{2}\right]^{0}$ complexes as compared with $\left[\mathrm{Co}^{\mathrm{III}}(\mathrm{chel}) \mathrm{L}_{2}\right]^{+}$greatly increases the relative importance of the equatorial chelating system in determining the $E_{\frac{1}{2}}^{\mathrm{II}}$ as compared with $E_{\frac{1}{2}}^{\mathbf{I}}$.

Methylcobalamine $\left(E_{\frac{1}{2}}^{\mathrm{I}}=-1.49 ; E_{\frac{1}{2}}^{\mathrm{II}}=-2.01\right)$ fits well into the series of our chelates. Ignoring the small difference between the methyl and ethyl radical, the half-wave potentials for methylcobalamine suggest that the corrin ring induces an electron affinity value intermediate between that caused by the salen or saloph dianions and that of $(\mathrm{DO})(\mathrm{DOH}) \mathrm{pn}$ monoanion.

\section{OXIDATION PROCESSES}

Oxidation processes such as

$$
[\mathrm{R}-\mathrm{Co}(\mathrm{chel}) \mathbf{L}] \stackrel{+\underset{+}{+}}{\stackrel{\mathrm{e}}{+}}[\mathrm{R}-\mathrm{Co}(\mathrm{chel}) \mathrm{L}]^{+}
$$

were revealed by anodic waves for organometallic derivatives only. Even in this case a reversible one electron transfer could be observed under suitable experimental conditions. 
Table 6

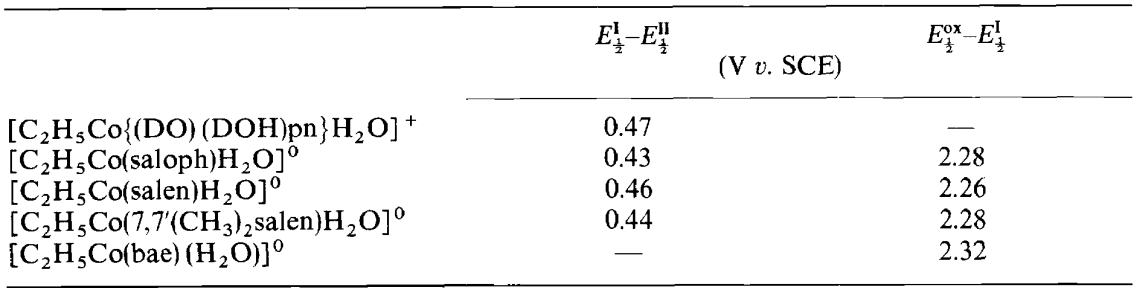

In considering the influence of the equatorial ligand on $E_{\frac{1}{2}}^{\mathrm{I}}, E_{\frac{1}{2}}^{\mathrm{I}}$ and $E_{\frac{1}{2}}^{\mathrm{ox}}$ for $\left[\mathrm{C}_{2} \mathrm{H}_{5}-\mathrm{Co}(\mathrm{chel}) \mathrm{L}\right]^{\circ}$ and $\left[\mathrm{C}_{2} \mathrm{H}_{5} \mathrm{Co}\{(\mathrm{DO})(\mathrm{DOH}) \mathrm{pn}\} \mathrm{L}\right]^{+}$it is noticeable that the differences $E_{\frac{1}{2}}^{\mathrm{II}}-E_{\frac{1}{2}}^{\mathrm{I}}$ and $E_{\frac{1}{2}}^{\mathrm{I}}-E_{\frac{1}{2}}^{\mathrm{ox}}$ are constant irrespective of the equatorial ligand (Table 6). This can be interpreted assuming that only the energies of the molecular orbitals involved are changed, going from one equatorial ligand to another, while the character of the orbitals is not drastically changed.

\section{ROLE OF THE EQUATORIAL LIGAND IN A REACTION MECHANISM INVOLVING RUPTURE AND FORMATION OF THE COBALT-CARBON BOND}

Three basic mechanisms can be distinguished in principle as far as the electron density distribution within the $\mathrm{Co}-\mathrm{C}$ bond in the transition state leading to cleavage is concerned: (a) the homolytic process yielding a $\mathrm{Co}^{\text {II }}$ derivative, (b) the heterolytic cleavage leaving the metal in the $\mathrm{Co}^{\mathrm{I}}$ formal oxidation state and (c) the heterolytic cleavage leaving the cobalt in the $\mathrm{Co}^{\text {III }}$ formal oxidation state.

We shall confine our attention to a reaction we recently reported which belongs to the third type, i.e. the transfer of the organic group from the cobalt atom of one chelate to that of another, both metal atoms remaining in the $\mathrm{Co}^{\text {III }}$ oxidation state.

By reacting a methylcobalt chelate with a diaquo derivative having a different equatorial ligand, the transfer of the methyl group takes place only when the chelating agent in the 'donor' complex precedes that of the 'acceptor' complex in a certain order ${ }^{54}$. The methyl group is thus transferred from the methylcobalt-bae to the diaquocobalt-salen or-saloph complexes following the reaction scheme (3)

$$
\begin{aligned}
{\left[\mathrm{CH}_{3} \mathrm{Co}(\text { chel }) \mathrm{H}_{2} \mathrm{O}\right]^{0} } & +\left[\mathrm{Co}\left(\text { chel }^{\prime}\right)\left(\mathrm{H}_{2} \mathrm{O}\right)_{2}\right]^{+} \\
& \rightarrow\left[\mathrm{Co}(\text { chel })\left(\mathrm{H}_{2} \mathrm{O}\right)_{2}\right]^{+}+\left[\mathrm{CH}_{3} \mathrm{Co}\left(\text { chel }^{\prime}\right) \mathrm{H}_{2} \mathrm{O}\right]^{0}
\end{aligned}
$$

The methyl-cobalt complex with any of the chelating dianions we are considering can transfer the methyl group to the diaquocobalt(DO) (DOH)pn chelate as is shown in the reaction (4)

$\left[\mathrm{CH}_{3} \mathrm{Co}(\mathrm{chel}) \mathrm{H}_{2} \mathrm{O}\right]^{0}+\left[\mathrm{Co}\{(\mathrm{DO})(\mathrm{DOH}) \mathrm{pn}\}\left(\mathrm{H}_{2} \mathrm{O}\right)_{2}\right]^{2+}$

$$
\rightarrow\left[\mathrm{Co}(\text { chel })\left(\mathrm{H}_{2} \mathrm{O}\right)_{2}\right]^{+}+\left[\mathrm{CH}_{3} \mathrm{Co}\{(\mathrm{DO})(\mathrm{DOH}) \mathrm{pn}\} \mathrm{H}_{2} \mathrm{O}\right]^{+}
$$


Furthermore, the aquocobalamine can act as acceptor towards the methylcobalt derivative of any of the chelating dianions but not towards that of the (DO) $(\mathrm{DOH})$ pn complex.

Using the $\left[\mathrm{Co}\{(\mathrm{DO})(\mathrm{DOH}) \mathrm{pn}\}\left(\mathrm{H}_{2} \mathrm{O}\right)_{2}\right]^{2+}$ complex as the methyl acceptor we found that the rate of the reaction decreased on changing the chelating agent in the methyl donor in the order bae $>$ salen $>$ methylcobalamine $^{55}$. In this series of experiments we obtained the methyl transfer reaction from a model organocobalt complex to aquocobalamine and from methylcobalamine to another model compound.

The reactivity of the chelates as methyl donors can be strongly enhanced by the reduction of the cobalt atom to a lower oxidation state ${ }^{47}$. In fact the $\mathrm{Co}^{\mathrm{I}}-\mathrm{CH}_{3}$ complex of the bis(DO) $(\mathrm{DOH})$ pn chelate which can be generated by electrochemical or by chemical means behaves as a methyl donor towards the starting $\mathrm{Co}^{\mathrm{III}}$ complex in the same reaction medium.

$$
\begin{aligned}
{\left[\mathrm{CH}_{3}-\mathrm{Co}^{\mathrm{I}}\{(\mathrm{DO})(\mathrm{DOH}) \mathrm{pn}\}\right]^{-}+\left[\mathrm{CH}_{3}-\mathrm{Co}^{\mathrm{III}}\{(\mathrm{DO})(\mathrm{DOH}) \mathrm{pn}\} \mathrm{H}_{2} \mathrm{O}\right]^{+} } \\
\rightarrow\left[\left(\mathrm{CH}_{3}\right)_{2}-\mathrm{Co}\{(\mathrm{DO})(\mathrm{DOH}) \mathrm{pn}\}\right]^{\mathrm{O}}+\left[\mathrm{Co}\{(\mathrm{DO})(\mathrm{DOH}) \mathrm{pn}\} \mathrm{H}_{2} \mathrm{O}\right]^{0}
\end{aligned}
$$

The product of the two electron reduction or of two one electron steps and its reaction with the starting complex was studied in the case of $\left[\mathrm{CH}_{3}-\right.$ $\left.\mathrm{Co}\{(\mathrm{DO})(\mathrm{DOH}) \mathrm{pn}\} \mathrm{H}_{2} \mathrm{O}\right]^{+}$by cyclic voltammetry. By this technique the disproportion of the one electron reduction product, i.e. a $\mathrm{Co}^{\text {II }}$ derivative, was shown to yield the bis organometallic derivative ${ }^{46}$.

The $\left[\left(\mathrm{CH}_{3}\right)_{2} \mathrm{Co}\{(\mathrm{DO})(\mathrm{DOH}) \mathrm{pn}\}\right]^{0}$ complex can act as a methyl group donor. In fact the dimethyl derivative is the best methyl donor of all the $\mathrm{Co}^{\mathrm{III}}-\mathrm{CH}_{3}$ complexes so far examined. The order of empirical methyl donor power is thus $\left[\left(\mathrm{CH}_{3}\right)_{2} \mathrm{Co}\{(\mathrm{DO})(\mathrm{DOH}) \mathrm{pn}\}\right]^{0}>\left[\mathrm{CH}_{3} \mathrm{Co}(\text { bae }) \mathrm{H}_{2} \mathrm{O}\right]^{0}>$ $\left[\mathrm{CH}_{3} \mathrm{Co}(\text { salen }) \mathrm{H}_{2} \mathrm{O}\right]^{0}>\left[\mathrm{CH}_{3} \mathrm{Co}(\right.$ saloph $\left.) \mathrm{H}_{2} \mathrm{O}\right]>$ methylcobalamine $>$ $\left[\mathrm{CH}_{3} \mathrm{Co}\{(\mathrm{DO})(\mathrm{DOH}) \mathrm{pn}\} \mathrm{H}_{2} \mathrm{O}\right]^{+}$. From this trend it can be concluded that the methyl donor power is determined both by the equatorial and the axial ligand, i.e. it is sensitive to both the cis and trans effect.

The transfer of the methyl group from a $\mathrm{Co}^{\mathrm{I}}$ derivative to a $\mathrm{Co}^{\mathrm{III}}$ complex, as well as the increase of the methyl donor capability in the dimethyl derivative. strongly suggests that the reaction can be formally considered as the transfer of a coordinated carbanion in the same sense as in the $\mathrm{Ag}^{+}$and $\mathrm{Hg}^{2+}$ assisted substitution of organic groups in the $\mathrm{Co}^{\text {III }}$ corrinoids yielding the corresponding aquoderivatives ${ }^{56}$. The release of the organic group is apparently favoured by the increase of the electronic charge at the metal atom both from the equatorial and by the trans axial ligand.

The strong influence of the chelating agent in the donor complex rules out the dissociation of the acceptor aquocomplex as the rate determining step. The reaction probably takes place through a binuclear intermediate containing the organic group as a bridging ligand and could thus be classified as a $\mathrm{S}_{\mathrm{E}} 2$ electrophilic substitution at the carbon atom, as was recently proposed for the reaction of the organocobaloximes and cobalamines with mercuric acetate $^{57}$.

The electronic effects on the equatorial plane can be so important that even a $\mathrm{Co}^{\mathrm{II}}$ complex can act as a methyl acceptor towards a $\mathrm{Co}^{\text {III }}$ chelate in spite of the higher formal oxidation state of the latter. This is shown in the 
reaction between $\left[\mathrm{CH}_{3} \mathrm{Co}(\mathrm{bae}) \mathrm{H}_{2} \mathrm{O}\right]^{0}$ and the $\left[\mathrm{Co}^{\mathrm{II}}(\mathrm{tfbae})\right]^{0}$ in which two methyl groups of the bae ligand are replaced by tritluoromethyl groups in the (tfbae) ligand. In this case it seems that an equilibrium is rapidly established ${ }^{58}$. On the other hand, it is worth noting the dramatic effect of the trans ligand: by exchanging merely the trans axial ligand from $\mathrm{H}_{2} \mathrm{O}$ to a methyl group in the (DO) (DOH)pn chelates one goes from one end to the other of the series of methyl donor complexes so far examined.

The evidence so far collected gives no information about steric effects. They are probably operative with more bulky organic groups and may be related to the possible displacement of the metal atom from the plane of the tetradentate ligand.

Let us now try to accommodate the experimental evidence about the influence of ligands on physico-chemical properties and on the trend of the reactivity, in a simple bonding scheme which is also relevant to the reaction mechanism involving the cobalt-carbon bond cleavage.

The well-known assumption that the $\pi$-electron delocalization is not confined within the equatorial ligand but involves also the metal d-orbitals is in keeping with the tendency towards planarity in the conjugate equatorial ligand in the tetra-coordinate complexes and with the values of coordination bond lengths in the equatorial plane. These bond lengths are particularly low compared to those in complexes having ligands where no conjugation occurs $^{27}$.

The fast electron exchange leading to reversible polarographic processes is also attributed to the lowering of the free energy differences which arise from the differences in the enthalpy and entropy of the $\mathrm{Co}^{\text {III }}$ and $\mathrm{Co}^{\text {II }}$ complexes. Thus it can be assumed that the electron affinity of the particle mainly represents the electron affinity of the molecular orbital accepting the electron. On the other hand, the parallel trend of the half-wave potentials suggests that the character of this orbital is not drastically altered by the change of the equatorial ligand, even when its energy is strongly influenced.

Table 7

Increasing 'donor power' of the organic group $\mathrm{R}$
Labilization of the axial ligand $\mathrm{L}$
Decreasing electron affinity
$\begin{array}{llllll}\mathrm{R}-\mathrm{Co}(\mathrm{s} a \text { len): } & \mathrm{R}= & \mathrm{C}_{6} \mathrm{H}_{5} \mathrm{CH}_{2} & \mathrm{C}_{6} \mathrm{H}_{5} & \mathrm{CH}_{3} & \mathrm{C}_{2} \mathrm{H}_{5} \\ E_{\frac{1}{2}}^{\mathrm{I}} \text { (V v. SCE) } & & -1.25 & -1.42 & -1.57 & -1.71\end{array}$

The most important effects so far considered, such as the labilization of the ligands; the lowering of the preferred coordination number; the mechanism of cleavage and the formation of the cobalt-carbon bond, concern the properties at the axial position. The axial bonds can now be discussed in a rough approximation by examining a simplified bonding scheme which involves one electron in each of the $\mathrm{d}_{\mathrm{z}^{2}}$ orbitals; one electron in the carbon orbital of the metal-carbon bond and the two electrons of the Lewis base lone pair in the coordination bond, in the trans position to the organic group. The electron transfer to the $\mathrm{Co}^{\text {III }}$ complexes implies that the lowest antibonding orbital is mainly formed from the $d_{z^{2}}$ and carbon orbital. 


\section{G. COSTA}

As the donor power of the ligand $\mathrm{R}$ increases, the character of the antibonding orbital becomes increasingly that of the carbon orbital (its energy increases and the electron affinity decreases). In the case of very strong donors, however, the lowest unfilled orbital may become $d_{x y}$ in character (as was shown from semi-empirical calculation for bisdimethylglyoximates) $\left(\right.$ Table 7) ${ }^{59,60,61}$.

The alternative charge distribution in the $\mathrm{Co}-\mathrm{C}$ bond after the electron transfer, leading to a potential carbanion as in the case of, for example, $\left[\mathrm{C}_{6} \mathrm{H}_{5}-\mathrm{Co}\right.$ (salen) $\left.\mathrm{H}_{2} \mathrm{O}\right]$ or, to reductive cleavage with formation of a $\mathrm{Co}^{\mathrm{I}}$ complex and $\mathrm{CH}_{3}$ as in the case of $\left[\mathrm{CH}_{3}-\mathrm{Co}\left(\right.\right.$ salen) $\left.\mathrm{H}_{2} \mathrm{O}\right]$, can be explained by the stronger donor power of the latter and by the different nature of the lowest unfilled orbital.

The transmission of the electronic effects and the labilization due to a strong $\sigma$-donor such as the organic group could also be discussed in terms of this extremely simplified bonding scheme. The bonding M.O. involved in the Co $-\mathrm{C}$ bond should become more $\mathrm{d}_{\mathrm{z}^{2}}$ in character with increasing energy of the carbon orbital. At the same time the trans axial ligand bond is labilized and the orbital involved in this bonding should become increasingly ligand in character.

How is the influence of the equatorial ligand explained? The main factor is probably again the effect on the $d_{z^{2}}$ orbital energy. The principal consequence is of course the possibility of formation of a stable organometallic bond. In going from the chelates of $(\mathrm{DO})(\mathrm{DOH})$ pn ligand to salen and bae derivatives the metal-carbon bonding orbital is stabilized while the electron affinity of the antibonding orbital is decreased, as is shown by the trend of half-wave potentials (Table 8). In the same order the trans Lewis base is increasingly labilized. In keeping with the concept of transmission of electronic effects, we may assume that the donor power of the equatorial ligand increases in the same order, i.e. from the (DO) (DOH)pn to bae.

\section{Table 8}

Increasing 'donor power' of the equatorial ligand

Labilization of the axial ligand

Decreasing electron affinity

$\mathrm{C}_{2} \mathrm{H}_{5}-\mathrm{Co}$ (chel)L: (DO) $(\mathrm{DOH}) \mathrm{pn}$ saloph salen $7,7^{\prime}\left(\mathrm{CH}_{3}\right)_{2}$ salen $\quad$ bae $\begin{array}{llllll}E_{\frac{1}{2}}^{\mathrm{l}}(\mathrm{V} v \text {. SCE }) & -0.93 & -1.54 & -1.71 & -1.80 & -1.97\end{array}$

We have seen that both the labilization of the axial ligand by the trans organic group and the influence of the equatorial ligand on the axial coordination bonds are related to the half-wave potential corresponding to the electron transfer. The trend of the chemical reactivity at the axial position can also be included in this pattern.

It was pointed out previously that the nucleophilicity of the $\mathrm{Co}^{\mathrm{I}}$ derivatives in the oxidative-addition reaction, including the formation of the cobaltcarbon bond from organic halides, is precisely reflected by the half-wave potential for the reduction from $\mathrm{Co}^{\text {II }}$ to $\mathrm{Co}^{\mathrm{I}}$ oxidation state $3,25,43,44$. The trend of increasing methyl donor power of the methylcobalt derivatives is assumed to be parallel to the trend of increasing negative charge on the 
cobalt atom. It is in fact reflected by the increasing cathodic value of the half-wave potential for the reduction from $\mathrm{Co}^{\mathrm{II}}$ to $\mathrm{Co}^{\mathrm{I}}$ oxidation state. The opposite trend seems to be shown by the methyl acceptor power which increases with increasing electrophilic character of the cobalt atom, i.e. going from bae to bisdiacetylmonoxime derivatives. On the other hand, the (parallel) trend of oxidation potentials, i.e. the trend of decreasing energy required to withdraw one electron from the particle, could be expected to reflect the tendency to nucleophilic reaction at the carbon atom.

The wide range of redox potentials spanned by the chelated under the influence of the different ligands is worth emphasizing. This of course shows how drastically the electron affinity of the particle can be affected. If these electron aftinity changes reflect the changes in effective charge on the cobalt atom, then even the charge distribution within the cobalt-carbon bond should be affected and the reaction mechanism at the cobalt-carbon bond may vary between the extremes of an electrophilic and nucleophilic reaction at the carbon atom, including of course the case of an homolytic mechanism. This approach may be useful in the understanding of the chemistry of the Vitamin $\mathrm{B}_{12}$ coenzymes containing the cobalt-carbon bond.

\section{ACKNOWLEDGEMENT}

Many of the contributions from our laboratory that I have presented have been made possible by the very capable and dedicated collaboration of the following of my co-workers: A. Bigotto, C. Cocevar, G. De Alti, E. Mestroni, G. Mestroni, G. Pellizer, A. Puxeddu, E. Reisenhofer, L. Stefani and G. Tauzher. Financial support of the Italian National Research Council and of the SNAM-Progetti is also gratefully acknowledged.

\section{REFERENCES}

1 G. N. Schrauzer, Accounts of Chemical Research 1 (4), 97 (1968).

2 P. S. Bratermann, R. C. Davier and R. J. P. Williams, in Adv. in Chem. Phys.. Vol. VII. p. 359. (ed. J. Duchesne) Interscience, New York (1964).

3 A. Bigotto, G. Costa, G. Mestroni. G. Pellizer, A. Puxeddu, E. Reisenhofer, L. Stefani and G. Tauzher, Inorg. Chim. Acta Rev. 4, 41 (1970).

4 C. Floriani and F. Calderazzo, J. Chem. Soc. $(A) 946$ (1969).

5 J. H. Bayson. N. K. King, F. D. Looney and M. E. Wienfield, J. Am. Chem. Soc. 91, 2775(1969).

6 A. L. Crumbliss and F. Basolo, Science 164, 1168 (1969). J. Am. Chem. Soc. 92.55 (1970).

7 G. N. Schrauzer and L. P. Lee, J. Am. Chem. Soc. 92, 1551 (1970).

8 (a) G. Costa, A. Puxeddu and L. Nardin Stefani, Inorg. Nucl. Chem. Letters 6, 191 (1970). (b) G. Tauzher, G. Costa, G. Amiconi, M. Brunori and E. Antonini, Nature 228, 549 (1970).

9 H. A. O. Hill, J. M. Pratt, R. J. P. Williams et al., J. Chem. Soc. 5964 (1964): 2859 (1965): 6485 (1965); 187 (1966): 453 (1968); 564 (1968); 2419 (1968); 2428 (1968); 381 (1969): 196 (1971); Biochem. J. 120, 263 (1970); J. Chem. Soc. (A) 1859 (1971).

10 H. A. O. Hill and K. G. Morallee, J. Chem. Soc. (A) 554 (1969).

11 G. N. Schrauzer, J. W. Sibert and R. J. Windgassen, J. Am. Chem. Soc. 90, 6681 (1968).

12 G. N. Schrauzer and E. Deutsch. J. Am. Chem. Soc. 91, 3341 (1969).

13 G. N. Schrauzer and J. W. Sibert, J. Am. Chem. Soc. 92, 1022 (1970).

14 G. N. Schrauzer, J. H. Weber and T. M. Beckham, J. Am. Chem. Soc. 92, 7078 (1970).

15 G. Costa, G. Mestroni, G. Tauzher and L. Stefani, J. Organomet. Chem. 6, 181 (1966).

16 G. Costa, G. Mestroni and L. Stefani, J. Organomet. Chem. 7, 493 (1967).

17 G. Costa and G. Mestroni, J. Organomet. Chem. 11, 325 (1968).

18 G. Costa, G. Mestroni and G. Pellizer, J. Organomet. Chem. 11, 333 (1968). 


\section{G. $\operatorname{CosTA}$}

19 G. Costa and G. Mestroni, Tetrahedron Letters 1781 (1967).

20 G. Costa and G. Mestroni, Tetrahedron Letters 1783 (1967).

21 G. Costa, G. Mestroni and G. Pellizer, J. Organomet. Chem. 15, 187 (1968).

22 G. Costa, G. Mestroni, G. Pellizer, G. Tauzher and T. Licari, Inorg. Nucl. Chem. Letters 5. 515 (1969): 7,57 (1971).

${ }^{23}$ G. Costa, G. Mestroni and G. Tauzher, J. Chem. Soc. $(A)$ in press.

24 G. Costa and G. Mestroni, Tetrahedron Letters 4005 (1967).

25 G. Costa, G. Mestroni and E. de Savorgnani, Inorg. Chim. Acta Rev. 3, 323 (1969).

26 G. Costa, G. Mestroni, T. Licari and E. Mestroni, Inorg. Nucl. Chem. Letters 5, 561 (1969).

27 M. Calligaris, G. Nardin and L. Randaccio, Coord. Chem. Rev. in press.

28 M. M. Harding and H. A. Long, J. Chem. Soc. (A) 2554 (1968).

${ }^{29}$ M. J. Barnet, H. C. Freeman, D. A. Buckingham, I. Nan Hsu and Van der Helm. Chem. Commun. 377 (1970).

30 J. Halpern and J. P. Mahler, J. Am. Chem. Soc. 87, 5361 (1965).

${ }^{31}$ R. A. Firth, H. A. O. Hill, J. M. Pratt, R. G. Thorp and R. J. P. Williams, J. Chem. Soc. (A) $2428(1968)$.

${ }^{32}$ H. A. O. Hill, B. E. Mann, J. M. Prath and R. J. P. Williams, J. Chem. Soc. (A) 564 (1968).

${ }^{33}$ H. A. O. Hill and K. G. Morallee, J. Chem. Soc. (A) 554 (1969).

${ }^{34}$ H. A. O. Hill, K. G. Morallee and G. Pellizer. J. Chem. Soc. (A) 2096 (1969).

${ }^{35}$ H. A. O. Hill, K. G. Morallee, G. Pellizer, G. Mestroni and G. Costa, J. Organomet. Chem. 11 , $167(1968)$

${ }^{36}$ G. Costa and L. Stefani, unpublished results.

${ }^{37}$ G. Tauzher, G. Mestroni, A. Puxeddu, G. Costanzo and G. Costa, J. Chem. Soc. $(A)$ in press.

${ }^{38}$ R. A. Firth, H. A. O. Hill, B. E. Mann, R. G. Thorp and R. J. P. Williams, J. Chem. Soc. $(A)$ 2419 (1968).

39 G. Costa, G. Tauzher and A. Puxeddu, Inorg. Chim. Acta Rev. 3, 41 (1969).

40 G. Costa, G. Tauzher and A. Puxeddu, Inorg. Chim. Acta Rev. 3, 45 (1969).

41 G. Costa, G. Mestroni, G. Tauzher, D. M. Goodall and H. A. O. Hill, Chem. Commun. 34 (1970).

42 H. A. O. Hill, J. M. Pratt and R. J. P. Williams, Discussions Faraday Soc. 47, 165 (1969).

${ }^{43}$ G. Costa. A. Puxeddu and G. Tauzher, Inorg. Nucl. Chem. Letters 4, 319 (1968).

${ }^{44}$ G. Costa, G. Mestroni, A. Puxeddu and E. Reisenhofer, J. Chem. Soc. 2870 (1970).

45 G. Costa, A. Puxeddu and E. Reisenhofer, Collection Czech. Chem. Commun. 36, 1065 (1971).

${ }^{46}$ G. Costa, A. Puxeddu and E. Reisenhofer, 1st Intern. Symposium on Biological Aspects of Electrochemistry, Rome 1971, in press.

47 G. Costa, A. Puxeddu and E. Reisenhofer. Chem. Commun. (1971) in press.

48 D. Konrad and A. A. Vleek, Collection Czech. Chem. Commun. 28, 808 (1963).

49 A. A. Vlcek. Electrochim. Acta 13, 1063 (1968).

50 R. E. Dessy, W. Kitching. T. Psarras, R. Salinger, A. Chen and T. Chivers, J. Am. Chem. Soc. 88, 460 (1966).

51 L. M. Ludwick and T. L. Brown, J. Am. Chem. Soc. 91, 5188 (1969).

52 W. C. Randall and R. A. Alberty, Biochemistry 5, 3189 (1966); 6, 1520 (1967): D. N. Hague and J. Halpern, Inorg. Chem. 6, 2059 (1967).

53 G. Costa, A. Puxeddu and E. Reisenhofer, unpublished results.

${ }^{54}$ G. Costa, G. Mestroni and C. Cocevar, Tetrahedron Letters 1869 (1971).

55 G. Costa, G. Mestroni and C. Cocevar, Chem. Commun. (1971) in press.

${ }^{56}$ H. A. O. Hill, J. M. Pratt, R. G. Thorp and R. J. P. Williams, Chem. Commun. 341 (1970).

${ }^{57}$ G. N. Schrauzer, J. H. Weber, T. M. Beckham and R. K. Y. Ho, Chem. Commun. 257 (1971).

58 A. Van der Bergen and B. O. West, Chem. Commun. 52 (1971).

59 G. De Alti, V. Galasso, A. Bigotto and G. Costa, Inorg. Chim. Acta Rev. 3, 533 (1970).

${ }^{60}$ G. De Alti. V. Galasso and A. Bigotto, Inorg. Chim. Acta Rev. 4, 267 (1970).

${ }^{61}$ M. Green, J. Smith and P. A. Taskev, Discussions Faraday Soc. 47, 172 (1969). 